\title{
Development of Correlation between Soaked CBR and In-Situ CBR Determined by DCP for Soil in the Southern Province of Rwanda
}

\author{
Eng. Naphtal NTIRENGANYA, Eng. Babiker Basher, Eng. Elsir Suliman Ahmed \& Dr. \\ Mohammed M. Shallal \\ Team Leader at Newtech Consulting Group
}

\begin{abstract}
In this paper, using Dynamic Cone Penetrometer (DCP), in-situ CBR tests have been carried out on 31 locations in Nyamgabe District in the Southern Province of Rwanda. The in-situ CBR results have been obtained from these tests. Thirty One tests pits were dug in the same locations and samples taken to the laboratory. Sieve Analysis, Atterburg Limits, Proctor and CBR tests were conducted on these samples. Accordingly a correlation has been developed between the In-Situ CBR using the DCP and the laboratory soaked CBR. The developed correlation helps to estimate the laboratory soaked CBR from the in-situ CBR using the DCP.
\end{abstract}

Key words: California Bearing Ratio, Dynamic Cone Penetrometer, Soil Classification,

\section{Introduction:}

Nondestructive tests are cheaper and quicker compared to the destructive tests. Several Correlations have been developed between the in-situ CBR using the Dynamic Cone Penetrometer (DCP) and the laboratory CBR. This paper is an attempt to develop a correlation on the laterite soil. Such correlations contribute to the scientific research and give a simple tool to be used for the rapid assessment of the bearing capacities in similar soils.

\section{Literature Preview:}

2.1 Dynamic Cone Penetrometer (DCP): The DCP is a labor intensive, non-destructive testing instrument designed for the rapid measurement of the in-situ strength of existing flexible pavements constructed with unbound materials. The DCP is a simple piece of equipment and easy to transport, maintain and operate. ${ }^{(1)}$ The DCP consists of a cone fixed to the bottom of a tall vertical rod. A weight is repeatedly lifted and dropped onto a coupling at the mid-height of the rod to deliver a standard impact, or 'blow', to the cone and drive it into the pavement. A vertical scale alongside the rod is used to measure the depth of penetration of the cone. Figure 1 shows an assembled DCP instrument, which uses an $8 \mathrm{~kg}$ hammer dropping through a height of $575 \mathrm{~mm}$ and a $60^{\circ}$ cone of $20 \mathrm{~mm}$ diameter. ${ }^{(1)}$ 


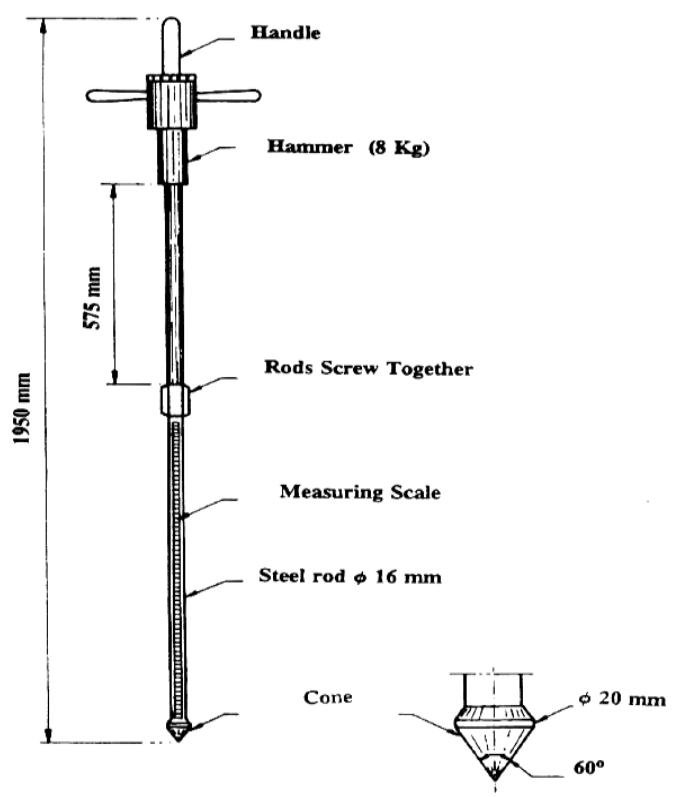

Figure 1: Dynamic Cone Penetrometer (DCP)

2.2 California Bearing Capacity (CBR): The California Bearing Ratio (CBR) test is a simple strength test that compares the bearing capacity of a material with that of a well-graded crushed stone (thus, a high quality crushed stone material should have a CBR equal to 100\%). It is primarily intended for, but not limited to, evaluating the strength of cohesive materials having maximum particle sizes less than $19 \mathrm{~mm}$ (0.75 in.). It was developed by the California Division of Highways around 1930 and was subsequently adopted by several federal American agencies and internationally (7). The basic CBR test involves applying load to a small penetration piston at a rate of $1.3 \mathrm{~mm}(0.05 ")$ per minute and recording the total load at penetrations ranging from $0.64 \mathrm{~mm}$ (0.025 in.) up to $7.62 \mathrm{~mm}(0.300$ in.),( AASHTO Designation: T19399(2007)) (26). Since the CBR test is a fairly easy and widely used test in Sudan, it has been decided to retain it as the quantitative means of evaluating the subgrade bearing strength. ${ }^{(2)}$

\subsection{Tests Location:}

This work has been carried out on soil in Nyamgabe District in the Southern Province in Rwanda. Thirty one different locations have been chosen to conduct both the DCP tests and the sampling for laboratory testing.

\section{Laboratory CBR:}

Disturbed samples represent 31 points have been collected and taken to the laboratory. Full testing comprising the Grain Size Distribution, Plasticity, Proctor \& CBR tests, has been carried out on these samples. Here under in table (1) is the obtained results:

Table (1): The obtained results for laboratory testing

\begin{tabular}{|c|c|c|c|c|c|}
\hline Sample No. & $\begin{array}{c}\text { \% Passing } \\
\text { Sieve } \\
\text { 0.08 mm }\end{array}$ & P.I\% & $\begin{array}{c}\text { M.D.D } \\
\text { T/m }\end{array}$ & O.M.C\% & $\begin{array}{c}\text { Lab. C.B.R\% } \\
\text { @ M.D.D 90\% }\end{array}$ \\
\hline S-1 & 29.9 & 11.1 & 1.959 & 11.7 & 10.0 \\
\hline S-2 & 28.5 & 9.1 & 1.991 & 11.1 & 13.5 \\
\hline S-3 & 30.0 & 10.0 & 1.989 & 10.9 & 13.5 \\
\hline S-4 & 29.9 & 9.2 & 1.894 & 10.5 & 12.0 \\
\hline S-5 & 36.9 & 10.8 & 2.080 & 10.9 & 10.0 \\
\hline S-6 & 35.1 & 9.6 & 1.803 & 11.3 & 13.5 \\
\hline S-7 & 33.5 & 10.4 & 1.852 & 8.9 & 11.2 \\
\hline S-9 & 34.0 & 10.6 & 1.828 & 9.6 & 11.8 \\
\hline S-10 & 40.4 & 8.6 & 1.810 & 13.9 & 13 \\
\hline
\end{tabular}




\begin{tabular}{|c|c|c|c|c|c|}
\hline S-11 & 16.3 & 0.0 & 1.868 & 12.1 & 11.5 \\
\hline S-12 & 21.6 & 0.0 & 1.934 & 12.3 & 14.7 \\
\hline S-13 & 54.9 & 7.2 & 1.702 & 20.0 & 11 \\
\hline S-14 & 53.6 & 8.4 & 1.695 & 19.3 & 16 \\
\hline S-15 & 30.8 & 12.7 & 1.885 & 13.0 & 9.3 \\
\hline S-16 & 23.8 & 8.8 & 1.680 & 18.8 & 9.4 \\
\hline S-17 & 51.8 & 8.4 & 1.702 & 19.4 & 10.8 \\
\hline S-18 & 25.9 & 0.0 & 1.991 & 10.0 & 15.6 \\
\hline S-19 & 44.7 & 8.8 & 1.880 & 14.0 & 10.4 \\
\hline S-20 & 45.8 & 0.0 & 2.029 & 9.3 & 10.5 \\
\hline S-21 & 26.9 & 0.0 & 1.918 & 12.8 & 17.1 \\
\hline S-22 & 57.9 & 0.0 & 1.677 & 20.9 & 12.5 \\
\hline S-23 & 44.0 & 0.0 & 1.995 & 13.7 & 12.5 \\
\hline S-24 & 53.6 & 0.0 & 1.919 & 18.8 & 12.5 \\
\hline S-25 & 38.0 & 8.9 & 1.727 & 15.9 & 14.2 \\
\hline S-26 & 55.3 & 10.5 & 1.774 & 14.4 & 16.6 \\
\hline S-27 & 57.7 & 12.4 & 1.766 & 10.7 & 16.8 \\
\hline S-28 & 43.0 & 9.9 & 1.765 & 15.0 & 17.8 \\
\hline S-29 & 54.1 & 9.9 & 1.769 & 12.1 & 17 \\
\hline S-30 & 52.4 & 0.0 & 1.818 & 14.7 & 16.2 \\
\hline S-31 & 33.7 & 0.0 & 1.840 & 13.6 & 14.5 \\
\hline
\end{tabular}

\section{In-Situ CBR:}

Using Dynamic Cone Penetrometer (DCP) with $8 \mathrm{~kg}$ hammer dropping through a height of $575 \mathrm{~mm}$ and a $60^{\circ}$ cone of $20 \mathrm{~mm}$ diameter, field tests have been conducted on the same stations where the samples were taken for laboratory testing. The in-situ CBR have been calculated and presented in the following table.

Table (2): The obtained results for In-situ C.B.R using DCP

\begin{tabular}{|c|c|}
\hline Sample No. & In-situ C.B.R using DCP \\
\hline S-1 & 28.7 \\
\hline S-2 & 26.1 \\
\hline S-3 & 16.0 \\
\hline S-5 & 29.6 \\
\hline S-6 & 32.1 \\
\hline S-7 & 16 \\
\hline S-9 & 20.3 \\
\hline S-10 & 17.7 \\
\hline S-11 & 16.0 \\
\hline S-12 & 20.0 \\
\hline S-13 & 18.7 \\
\hline S-14 & 13.7 \\
\hline S-16 & 19.8 \\
\hline S-17 & 12.4 \\
\hline S-18 & 24.4 \\
\hline S-19 & 24.1 \\
\hline S-21 & 20.3 \\
\hline S-22 & 12.8 \\
\hline & 21.3 \\
\hline & 21.1 \\
\hline & 11.4 \\
\hline & 16.95 \\
\hline
\end{tabular}




\begin{tabular}{|c|c|}
\hline S-23 & 16.9 \\
\hline S-24 & 16.9 \\
\hline S-25 & 14.4 \\
\hline S-26 & 11.8 \\
\hline S-27 & 11.7 \\
\hline S-28 & 10.8 \\
\hline S-30 & 11.4 \\
\hline S-31 & 12.1 \\
\hline & 13.9 \\
\hline
\end{tabular}

\section{Analysis:}

5.1 Data for Analysis: The following table shows the obtained data for Lab. C.B.R\% @ M.D.D 90\% versus the In-situ C.B.R using DCP for each location:

Table (3): Lab. C.B.R\% and In-situ C.B.R using DCP at each station:

\begin{tabular}{|c|c|c|}
\hline Sample No. & Lab. C.B.R\% @ M.D.D 90\% & In-situ C.B.R using DCP \\
\hline S-1 & 10.0 & 28.7 \\
\hline S-2 & 13.5 & 26.1 \\
\hline S-3 & 13.5 & 16.0 \\
\hline S-4 & 12.0 & 29.6 \\
\hline S-5 & 10.0 & 32.1 \\
\hline S-6 & 13.5 & 16 \\
\hline S-8 & 11.2 & 20.3 \\
\hline S-9 & 11.8 & 17.7 \\
\hline S-10 & 13 & 16.0 \\
\hline S-11 & 10.9 & 20.0 \\
\hline S-13 & 11.5 & 18.7 \\
\hline S-14 & 14.7 & 13.7 \\
\hline S-15 -16 & 11 & 19.8 \\
\hline S-17 & 16 & 12.4 \\
\hline S-18 & 9.3 & 24.4 \\
\hline S-19 & 9.4 & 24.1 \\
\hline S-20 & 10.8 & 20.3 \\
\hline S-22 & 15.6 & 12.8 \\
\hline S-23 & 10.4 & 21.3 \\
\hline S-24 & 10.5 & 21.1 \\
\hline S-25 & 17.1 & 11.4 \\
\hline S-26 & 12.5 & 16.95 \\
\hline S-27 & 12.5 & 16.9 \\
\hline S-29 & 12.5 & 16.9 \\
\hline S-30 & 14.2 & 14.4 \\
\hline S-31 & 16.6 & 11.8 \\
\hline & 16.8 & 11.7 \\
\hline & 17.8 & 10.8 \\
\hline 17 & 11.4 \\
\hline & 16.2 & 12.1 \\
\hline & 14.5 & 13.9 \\
\hline
\end{tabular}

The following chart represents the obtained data of laboratory CBR Versus the In-Situ CBR using DCP: 


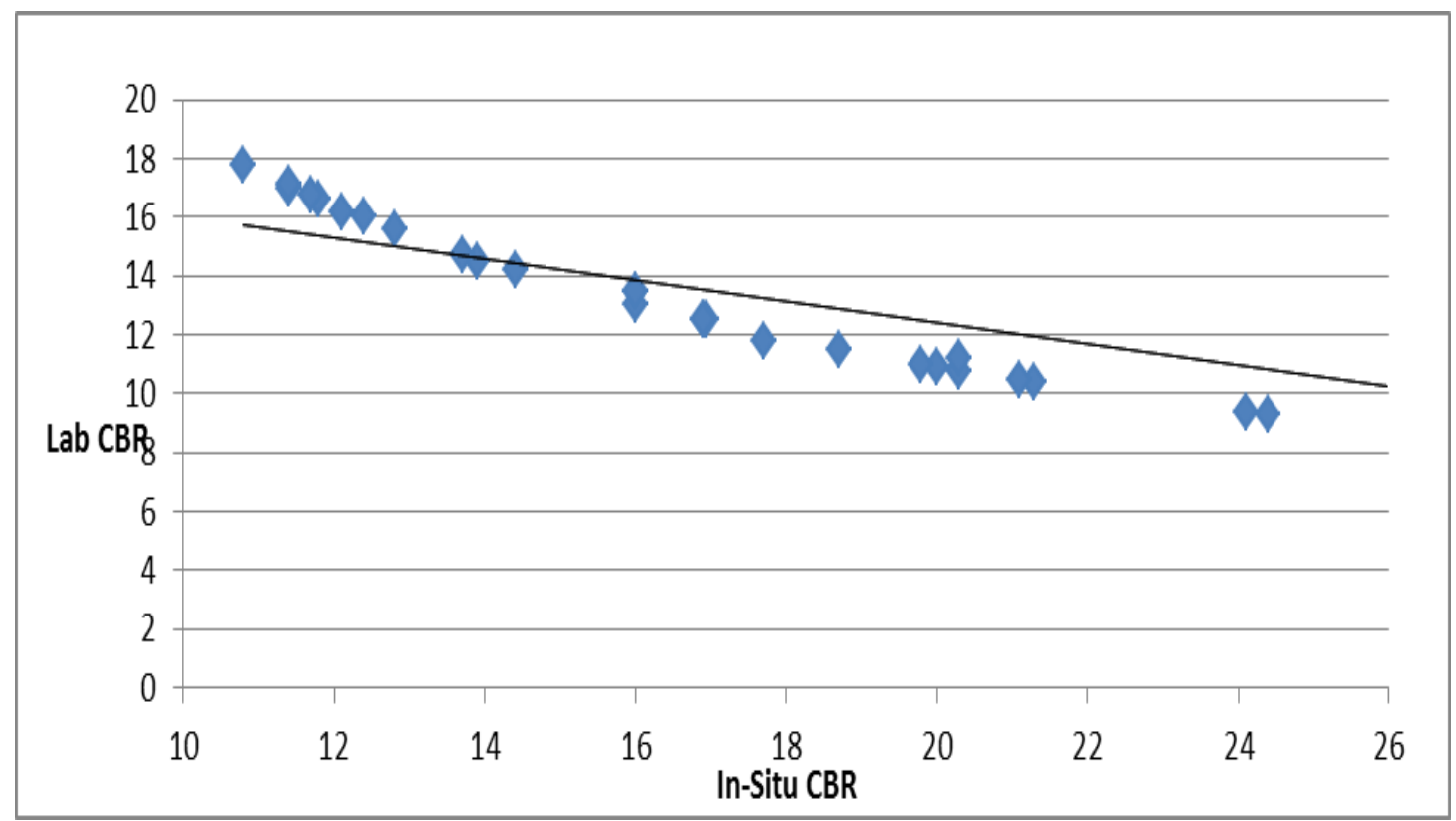

Figure (1): CBR Vs In-Situ CBR using DCP

\subsection{Development of Correlation:}

Statistical analysis has been carried out to obtain the regression relationship between the two variables. The concept of regression analysis deals with finding the best relationship between $\mathrm{Y}$ and $\mathrm{x}$, quantifying the strength of that relationship, and using methods that allow for prediction of the response values given values of the regressor $\mathrm{x}$.

In our case the independent variable is the (the In-Situ CBR using DCP) and the dependent variable is the (laboratory CBR). The independent variable is called the regressor. A reasonable form of a relationship between the response $\mathrm{Y}$ and the regressor $\mathrm{x}$ is the linear relationship

$$
\mathbf{Y}=\boldsymbol{\beta 0}+\boldsymbol{\beta 1} \mathbf{x}+\boldsymbol{\mu} \text {. }
$$

Where, of course, $\boldsymbol{\beta} \mathbf{0}$ is the intercept and $\boldsymbol{\beta 1}$ is the slope, $\boldsymbol{\mu}$ is a random variable.

The statistics calculator (Stat Pac, version 4) has been used to develop the following correlation:

$\mathrm{Y}=\mathbf{4 2 . 0 4 7}-\mathbf{1 . 8 2 7} \mathrm{x}+\mathbf{3 . 3 7 9}$

Where:

$\boldsymbol{\beta 0}=42.047, \boldsymbol{\beta 1}=1.827, \boldsymbol{\mu}=3.379$

For the above correlation equation, R- squared found equal to 0.67 .

\section{Conclusion and Recommendation:}

Based on the results of this research study, the correlation equation been developed, provides a reliable alternative for indirect determination of CBR based on the in-situ CBR using DCP for soils with the same characteristics.

\section{References:}

[1] User Guide to the Dynamic Cone Penetrometer, Minnesota Department of Transportation.

[2] Piouslin Samuel and Simon Done, TRL, DCP analysis and design of low volume roads.

[3] Standard Specifications for Transportation Materials and Methods of Sampling and Testing, American Association of State Highway and Transportation Officials, $29^{\text {th }}$ Edition, 2009.

[4] Nature and Properties of Lateritic Soils Derived from Different Parent Materials in Taiwan, The Scientific World Journal Volume 2014.

[5] Ronald E. Walpole, Raymond H. Myers, Sharon L. Myers \& Keying Ye "Probability \& Statistics for Engineers \& Scientists", 2012, published by Pearson Education.

[6] William Navidi, "Statistics for Engineers and Scientists", Third Edition, published by (Mc GrawHill), 2011. 